\title{
Device for simultaneous recovery and containment of spilled oil from the seawater surface
}

\author{
J. Rodríguez, A. Ramírez \& M. Martínez \\ Department of Mechanical Engineering, \\ Central University of Venezuela, Venezuela
}

\begin{abstract}
Oil spills constitute a major water pollution problem due to their impact on the environment. Such spills may be controlled through containment and recovery and some commercial systems are available to this end, some of which have been developed using mechanical methods. Some conventional equipment can recover floating oil spills while others can contain them. Recovery and containment equipment need to work in conjunction to recover and contain simultaneously. This would imply that two sets of equipment should operate at the same time. In this study, a description of a floating mechanical device for both the recovery and containment of spilled oil from the sea surface is presented. This device is made up of cylindrical sections that can be connected in series to provide a containment barrier also capable of recovering floating pollutants while the spill is being contained. Identification of the oil spill determines the number of sections required. The device can contain and recover oil spills simultaneously with or without a defined water/oil interface. If the layer of polluting agent lies in calm waters it is decanted by means of interconnected cylindrical recoverers/containers and the polluting agent is then suctioned into each section through a common vacuum line. On the other hand, if the water/oil interface is not defined due to strong waves, the polluting agent adheres to a rotary cylindrical mesh that envelops the device, inducing the flow of the floating pollutants into the recoverers/containers. In contrast to other available devices, it makes use of the suctioned oil/water energy to turn the rotary mesh. The shape and the arrangement of its constituent parts help make the device an ideal piece of light mechanical equipment.
\end{abstract}

Keywords: recovery, containment, heavy surge, calm water, spilled oil. 


\section{Introduction}

Although only $2 \%$ the world's sea and river oil pollution comes from coastal oil plants, its impact is significant due to the wide biodiversity that exists in these zones and the importance that tourism and the fishing industry represents for the communities that inhabit such areas [1]. The main equipment currently used in Venezuela to control oil spills are floating containment barriers and floating recoverers. The barrier contains oil from the surface of the water and the containers remove and recover oil from the surface [2]. However, floating recoverers cannot contain the oil spilled; they need to operate alongside floating barriers to contain the oil that is to be recovered. For this reason, cleanup methods are troublesome.

The device presented in this study [3] is based on the fusion between a cylindrical floating barrier and a rotating drum recoverer or adhesion skimmer [4]. This means that the cleanup method is greatly simplified in terms of the equipment used. Another advantage is its versatility. The equipment works under different operating conditions. The first is for calm waters in which the device operates like a large weir to control oil spilled in refineries and harbors. The second is for conditions of heavy surge, applicable in cases of offshore spills where the water-oil interface is irregular and the device operates as an adhesion recoverer. Its ability to both contain and recover oil spills simultaneously has led the device to be called the SCR - Simultaneous Containment and Recovery device.

\section{SCR performance as a recoverer}

If the oil spilled is contained and immobilized, the collection process will be speeded up using the SCR equipment. Oil spill identification will determine the number of sections required.

\subsection{Heavy surge condition}

The SCR equipment is basically a cylindrical weir (1), as shown in Fig. 1. A tube-shaped mesh (2) turns around the cylinder and as it does so, produces a surface flow in the contained zone, inducing the floating pollutants (3) beneath the water surface (4). The pollutants are accumulated on the facing boundary (5) where the oil is contained (6). When the water-oil interface spills over the top of the weir (3), it is decanted in (1). Finally, oil is suctioned through a common vacuum line (8). Note that in the zone where there is water (4) at the weir, this water is intentionally induced to maintain the oil on the suction hole. Fig. 2 shows two SCR models connected next to a car so as to appreciate their respective sizes Also, an SCR Model operating in the Cardon refinery in Venezuela is shown, as well as a sketch of an SCR model operation in heavy surge. 


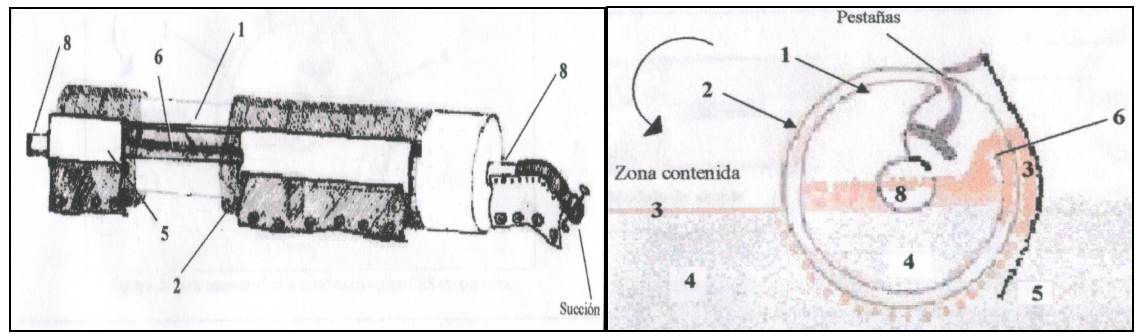

Figure 1: $\quad$ SRC Sketch and SRC cross section.

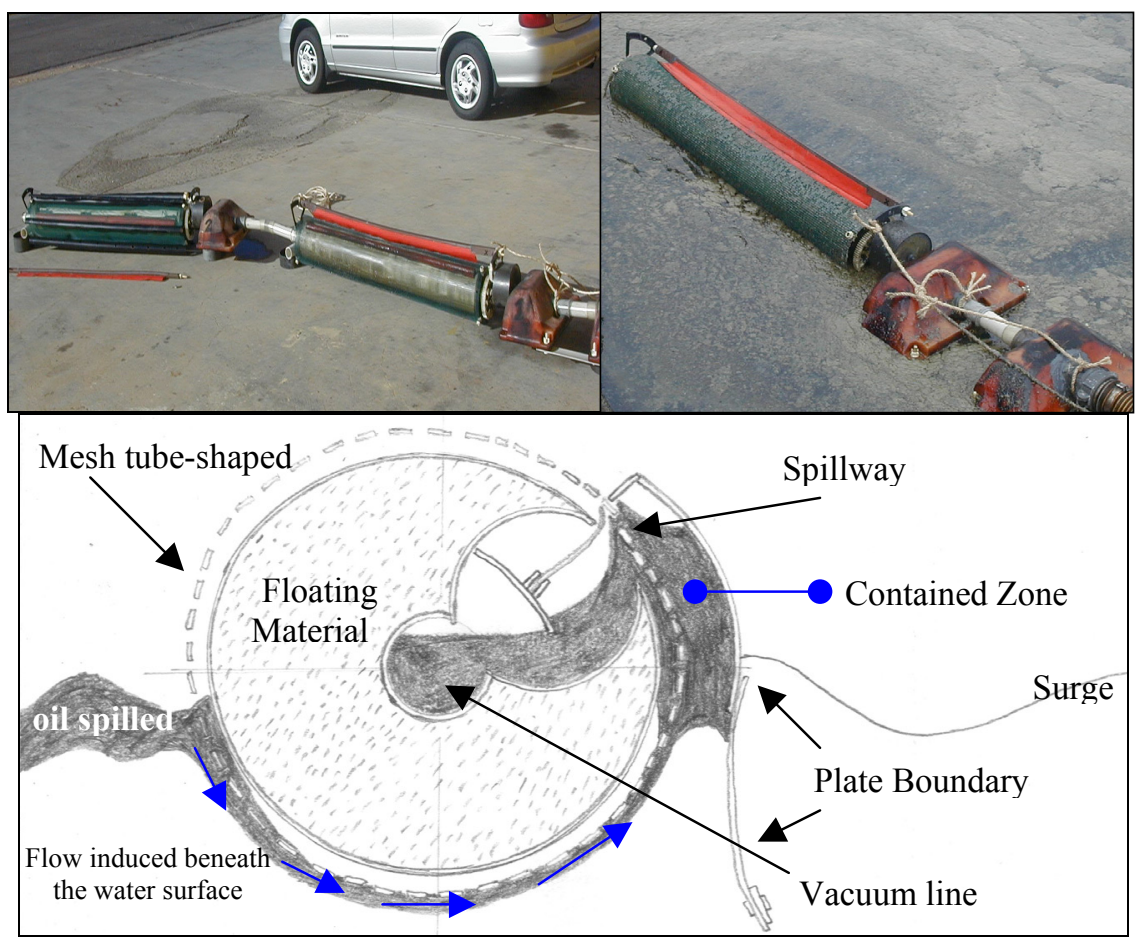

Figure 2: Two SRC models connected, SRC Model working in Cardon refinery Venezuela 2004, and sketch of SRC model working in heavy surge.

\subsection{Power pack for recollection on heavy surge}

The SCR operates to an external vacuum pump. To achieve this, it is necessary to use high suction capacity pumps attached to long hoses to allow the device to float freely. Figure 3 shows a suction truck. When the equipment is working, there is suction in the vacuum line, which has a mechanism that uses the suctioned oil-water energy to rotate the rotary tube-meshed mesh. 


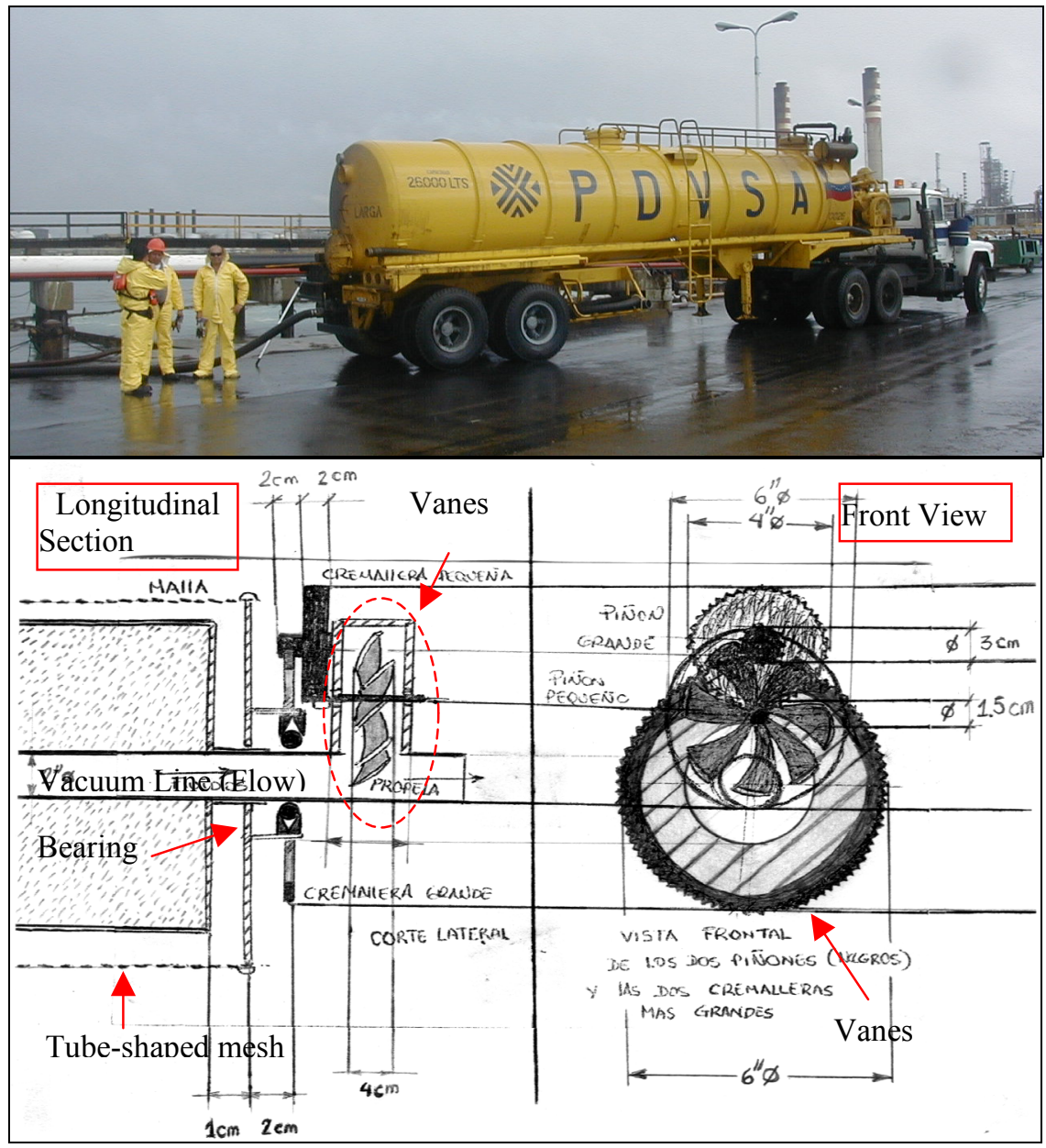

Figure 3: Vacuum truck, Cardon Refinery - Petroleos de Venezuela S.A. PDVSA. 2004, and Sketch of the rotation device for the tubeshaped mesh.

\subsection{Calm waters condition}

When there is little or no wave movement, the water-oil interface thickness is perfectly delimited. Under this condition, it is not necessary to use energy to rotate the cylindrical mesh since, when the oil is highly selective when it is decanted. When the oil spill occurs, the SCR will act only as a weir (1) because the tube-shaped mesh (2), the shape of the boundary plate (5), and the mechanism to rotate the tube-shaped mesh (10) will not be used. Fig. 4 shows a SCR Model connected and a model sketch of clam waters operations. 

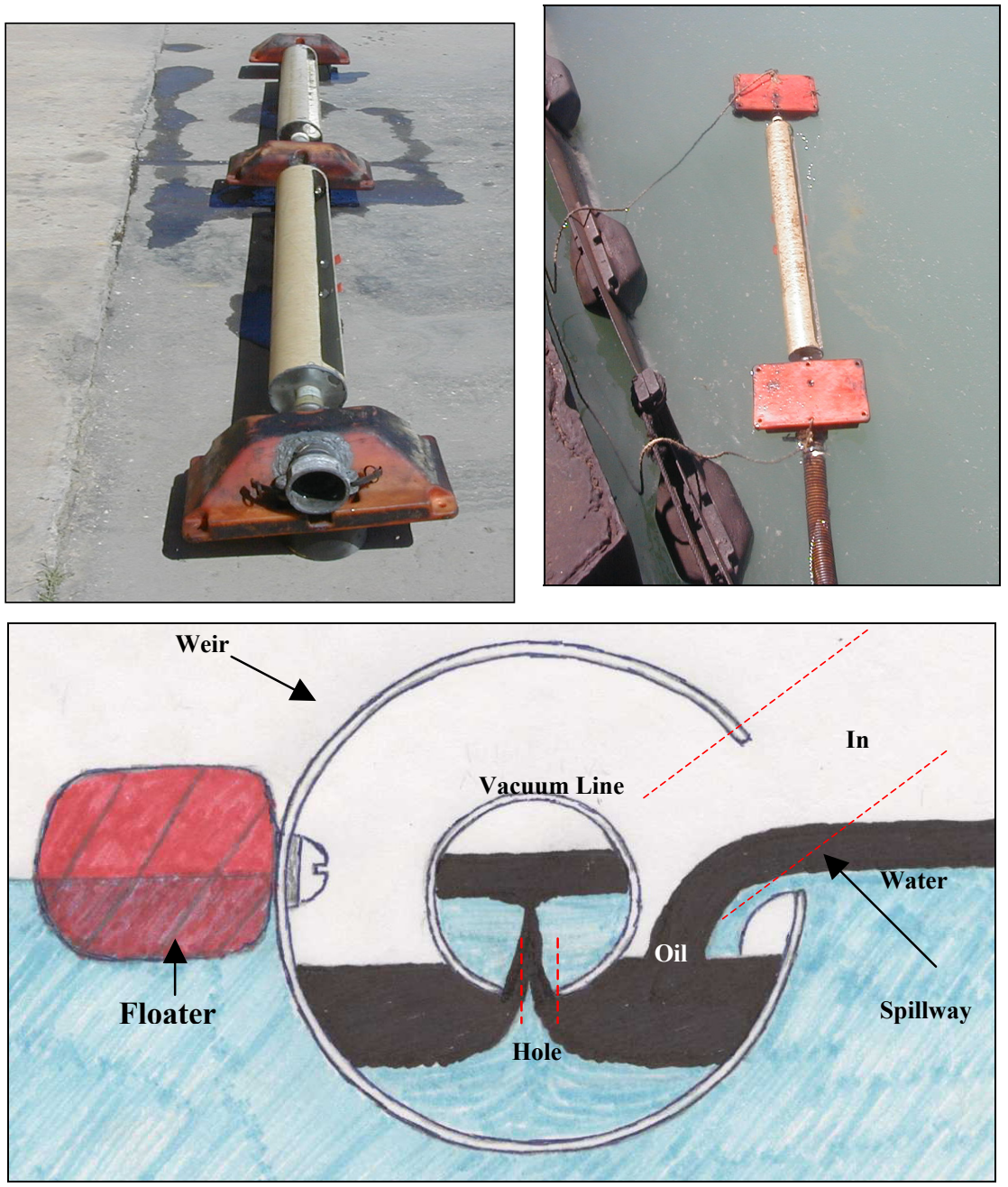

Figure 4: Two SRC models connected for calm waters, SRC model for calm waters working (Cardon Refinery - PDVSA, 2004), and SRC model sketch working in calm waters condition (cross section).

\subsection{Power pack for collection in calm waters}

Vacuum pumps provide the ideal suction power pack to operate SCR equipment. The oil flows into the weir where it collects the recovered water-oil mixture which is then either pumped or sucked from the weir. 


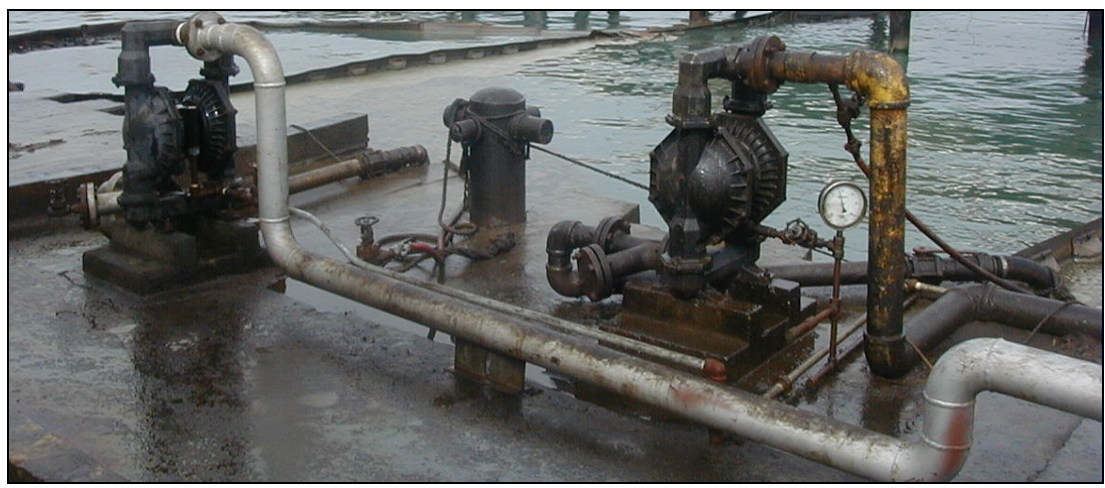

Figure 5: Vacuum pumps. Cardon Refinery. PDVSA - Venezuela. 2004.

\section{SCR performance as a recoverer and barrier}

Spilled oil will be contained and recovered simultaneously if the SCR equipment is connected in series. Under this arrangement, each part individual SCR becomes a section of a large articulated SCR Barrier. Identification of the oil spill determines the number of sections required and the length of each connected piece of equipment. The power pack should be powerful enough to guarantee that it functions correctly along the entire length of the vacuum line. Figure $2 \mathrm{C}$ shows the center or vacuum line.

\subsection{SCR operation as a barrier in heavy surge}

In this condition, each section works as a rotating drum recoverer or skimmer. The difference between the model presented here and more conventional models is that the oil-water mixture flow increases sequentially as it moves through the sections until it reaches that one attached to the vacuum pump line section, where it is then pumped or sucked into a storage tank. In heavy surge, this arrangement facilitates offshore cleaning up sweeping proceses.

\subsection{SCR operation as a barrier in calm waters}

In this condition, each section works as a weir recoverer, and like the barrier in heavy surge, it requires a powerful but intermittent suctioned energy to guarantee it works well throughout the vacuum line. In this condition it is not possible to sweep since it would force only water flows into the weir, due to the wave height that is formed. This implies the system is somewhat inefficient in this sense.

\section{Advantages}

SCR systems use an oil-water mixture to rotate their tubular meshes, unlike other available equipment. This is because the adhered weight is relatively low and hence there is no need for so much force from inertia if the oil has a higher 
viscosity. Furthermore, the versatile nature of the SCR makes it possible to be adapted to the two main operating conditions mentioned previously. The fact that the equipment is light makes its easy to set in place and to manoeuvre. Conventional equipment uses hydraulic systems to rotate its tubular surfaces, thus increasing weight and making the device mechanically complex [5]. The SCR device makes use of the energy from the air-oil-water mix to rotate the mesh in heavy surge conditions, due to the fact that the mass of oil that adheres to the SCR mesh or to the conventional drum is relatively small and does not require a substantial increase in inertia that is necessary to break (Fig 6).

$$
\begin{gathered}
V_{h}=\sigma_{h} * L_{T} * \theta_{T} * \pi \\
P_{\text {add }}=V_{h} \times \rho_{h} \times g
\end{gathered}
$$

Where:

mh: Adhered oil mass

$\rho$ h: Adhered oil density

Vh: Adhered oil Volume

oh: Oil Layer thickness

$\theta \mathrm{T}$ : Drum diameter

LT: Drum Length

Padd: Additional weight

g: Gravity.

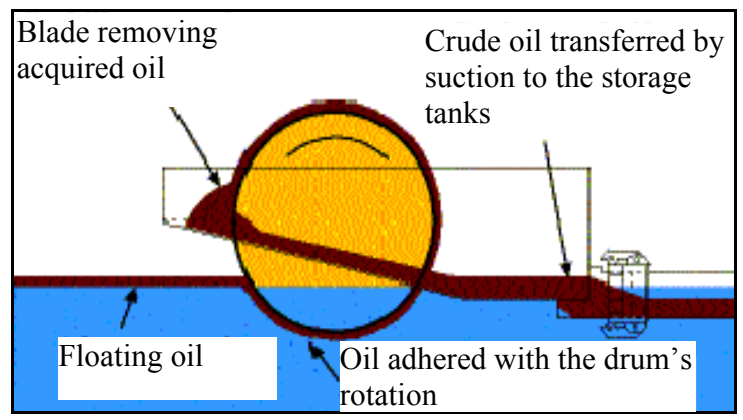

Figure 6: Performance sketch of the conventional drum recoverer.

\section{Conclusion}

This study describes and highlights the advantages of an innovative design of a mechanical floating device for simultaneous recovery and containment of spilled oil from the water surface, for medium and low levels of viscosity, operated by vacuum pressure, suitable both for single or series connected operational use. 


\section{References}

[1] Battelle, Study of effects of oil discharges and domestic and industrial wastewaters on the fisheries of Lake Maracaibo, Venezuela, Report to Creole Petroleum Corporation, Caracas. 1974.

[2] OMI Manual sobre la contaminación ocasionada por hidrocarburos (Manual Part IV). International Maritime Organization, London 2001.

[3] Rodríguez, Propuesta para el diseño de un equipo para la contención y recolección simultanea de hidrocarburos flotantes en grandes cuerpos de agua. Undergraduate Especial Work. Experimental National University Antonio Jose de Sucre. Barquisimeto Venezuela, 2003.

[4] ELASTEC, Oil spill equipment, www.elastec.com

[5] NOAA, Hábitats Costeros Característicos. Selección de Alternativas para Responder a Derrames de Petróleo (Manual). Ocean and atmospheric national administration, Oceanic National Service, dangerous materials attention division. pp 10, 2001. 